\title{
LIMITES E POSSIBILIDADES DA INOVAÇÃO COMO ESTRATÉGIA EM ORGANIZAÇÕES PÚBLICAS
}

\author{
LIMITS AND POSSIBILITIES OF INNOVATION AS STRATEGY IN PUBLIC \\ ORGANIZATIONS
}

\section{LÍMITES Y POSIBILIDADES DE INNOVACIÓN COMO ESTRATEGIA EN LAS ORGANIZACIONES PÚBLICAS}

\begin{abstract}
Scheine Neis Alves da Cruz De Bastiani
Mestre em Administração pela Universidade do Sul de Santa Catarina; Professora da Universidade Alto Vale do Rio do Peixe e da Faculdade de Tecnologia Senac Caçador scheine.cruz@gmail.com
\end{abstract}

\section{Taisa Dias}

Doutora em Administração pela Universidade Federal de Santa Catarina; Professora na Fundação ENA Escola de Governo do Estado de Santa Catarina taisadias.adm@gmail.com

\section{Simone Sehnem}

Doutora em Administração e Turismo pela Universidade do Vale do Itajaí; Professora Pesquisadora no Mestrado Profissional em Administração da Universidade do Oeste de Santa Catarina simone.sehnem@unoesc.edu.br

\section{Contextus}

ISSNe 2178-9258

Organização: Comitê Científico Interinstitucional Editor Científico: Marcelle Colares Oliveira Avaliação : Double BlindReview pelo SEER/OJS Revisão: Gramatical, normativa e de formatação Recebido em 15/12/2014 Aceito em 25/11/2015 $2^{\mathrm{a}}$ versão aceita em 11/12/2015 $3^{\text {a }}$ versão aceita em 21/12/2015

\section{RESUMO}

Este artigo tem como objetivo analisar a taxonomia da relação universidade-empresa de Bonaccorsi e Piccaluga (1994), ao buscar seus limites e suas possibilidades quando aplicada às organizações públicas e ao destacar que a inovação também pode ser empregada como estratégia em instituições dessa natureza. O método empregado foi o de levantamento descritivo-interpretativista, que se caracteriza predominantemente como qualitativo, com aplicação de um questionário aos egressos de mestrados profissionais em Administração Pública. Os resultados apontam que essa taxonomia pode ser aplicada às organizações públicas, já que todos os casos analisados conseguiram se enquadrar em pelo menos uma de suas categorias. Porém, para alcançar o sucesso dentro desse contexto, são necessárias algumas adequações, principalmente nas terminologias utilizadas, visto que evidenciam o foco nas organizações de mercado. Todo esse passeio pela teoria permitiu não o aprimoramento, mas a abertura de um espaço para desenvolvimentos posteriores do conhecimento, tendo em mente a necessidade perene de construções e reconstruções.

Palavras-chave: Inovação. Estratégia. Relação universidade-empresa. Administração pública. Organizações públicas. 


\begin{abstract}
This article aims to analyze the Bonaccorsi e Piccaluga (1994)'s taxonomy, seeking its limits and its possibilities when applied to public organizations, highlighting that innovation can also be used as a strategy in such organizations. The method used was the descriptive and interpretative survey by predominantly qualitative approach and the application of a questionnaire to public administration professional masters. The results show that this taxonomy can be applied to the public, since all the cases analyzed were able to fit in at least one of their categories. But to succeed in this context are needed some adjustments, mainly in the terminology used, as evidenced focus on market organizations. All this tour allowed by the theory, if not improving, opening a space for further development of knowledge, keeping in mind the perennial need for constructions and reconstructions.
\end{abstract}

Keywords: Innovation. Strategy. University-company. Public administration. Public organizations.

\title{
RESUMEN
}

Este artículo tiene como objetivo analizar la taxonomía de la relación universidad-empresa de Bonaccorsi y Piccaluga (1994), en busca de sus límites y sus posibilidades cuando se aplica organizaciones públicas, destacando que la innovación también se pueden emplear como estrategia en tales organizaciones. El método empleado fue a la encuesta descriptivo e interpretativo, caracterizado por ser predominantemente cualitativa, con la aplicación de un cuestionario a maestros de la administración publica. Los resultados muestran que esta taxonomía se puede aplicar a las organizaciones públicas, ya que todos los casos analizados fueron capaces de encajar en al menos uno de sus categorías. Pero para tener éxito en este contexto, son necesarios algunos ajustes, sobre todo en la terminología utilizada, como se evidencia en el foco organizaciones de mercado. Todo este recorrido permitido por la teoría, si no mejorar, la apertura de un espacio para la evolución futura de los conocimientos, teniendo en cuenta la necesidad perenne para las construcciones y reconstrucciones.

Palabras clave: Innovación. Estrategia. Universidad-empresa. Administración pública. Organizaciones públicas.

\section{INTRODUÇÃO}

Num contexto caracterizado por inovações, encontram-se em destaque as relações interorganizacionais, as quais vislumbram a cooperação entre organizações para a concretização de objetivos por meio de ações de ajuda mútua e, assim, a sustentabilidade da postura organizacional inovativa. Da mesma forma, encontra-se a relação estabelecida com as Instituições de Ensino Superior (IES), que fornecem o conhecimento científico às organizações, principalmente para os setores de Pesquisa e Desenvolvimento (P\&D) na busca por inovação, e ainda a relação contrária, nas quais as organizações se tornam fontes de embasamento empírico para as pesquisas acadêmicas (NELSON, 2006), desempenhando um papel importante no ambiente do Sistema Nacional de Inovação (SNI).

Apesar da industrialização tardia do Brasil e, devido a essa trajetória histórica, do fato de ter seu SNI ainda pouco dinâmico, observa-se que a cooperação 
entre as IES e as organizações no cenário nacional vem sendo investigada como uma opção estratégica para o desenvolvimento de novos conhecimentos e de competências necessárias às últimas (GONÇALO; ZANLUCHI, 2011). Esse fato se evidencia, pois os responsáveis por tomar decisões nas organizações estão percebendo as alterações no processo de inovação, que não mais acontece apenas internamente, mas também é influenciado e impulsionado por atores externos, que podem dividir custos, riscos, pesquisas e testes (BIGNETTI, 2002).

Bonaccorsi e Piccaluga (1994) elaboraram uma taxonomia dessa relação universidade-empresa, ou seja, depois de superadas as barreiras e a relação estabelecida, dependendo de como foi construída, receberá uma denominação específica. No entanto, até onde foi possível estudar, essa taxonomia não acolhe a realidade de organizações não mercado, não sendo, também, possível perceber se a inovação é considerada nesse grupo.

Tendo como base os três tipos organizacionais descritos nos estudos de França-Filho (2004), ou seja, as organizações "de mercado", "públicas” e "associativas", foi possível delimitar o enfoque para a realização deste estudo, pois, por meio da interpretação das teorias, percebeu-se a predominância do cunho econômico e do objetivo competitivo a partir da estratégia de inovação e das relações interorganizacionais. Logo, notase que os conceitos básicos dessas relações estão constantemente ligados às organizações de mercado, ou seja, voltadas ao lucro (empresas). Com isso, tanto o governo como as organizações públicas que o alicerçam são apontados apenas como fomentadores do processo inovativo, esquecendo-se do fato de que essas organizações, tais como quaisquer outras, também necessitam de inovação para o aperfeiçoamento de seus processos e, assim, para a satisfação com excelência da dignidade dos cidadãos. Ratificando esse contexto, Klering e Andrade (2006, p. 77) enfatizam a "ampla e diversa apresentação do conceito de inovação na literatura de administração". Contudo, observam, como oportuno, o aumento de seu entendimento a partir de outras perspectivas e setores, principalmente, dentro do contexto do setor público.

É importante destacar, então, que, com o intuito de obter uma visão madura das contribuições da interação não apenas com organizações de mercado, mas também com as organizações não mercado (FRANÇA-FILHO, 2004), buscou-se analisar especificamente a taxonomia da relação universidade-empresa estruturada por Bonaccorsi e Piccaluga (1994) quando aplicada às organizações não mercado com 
base na perspectiva dos alunos de Mestrados Profissionais em Administração Pública. Dessa forma, valorizou-se o campo da Administração Pública, bem como as pesquisas desenvolvidas dentro dele e o resultante desenvolvimento científico da área. Tem-se; portanto, como alvo de pesquisa, o comportamento da taxonomia em um novo contexto, o das organizações não mercado. Para permitir essa análise, seus preceitos foram apresentados aos alunos egressos dos Mestrados Profissionais em Administração Pública, como já mencionado, percebendose ali um campo fértil para a discussão, já que esses indivíduos estão imersos na realidade não mercado e, pela característica profissional do curso, por buscarem contribuições mais efetivas e mensuráveis ao cotidiano organizacional.

Diante dessas considerações e da realidade da taxonomia de Bonaccorsi e Piccaluga (1994), a qual é considerada pelos grupos de pesquisa na área da relação universidade-empresa a mais importante, tendo seus conceitos amplamente utilizados, especialmente dentro do contexto de organizações de mercado, emerge-se a seguinte pergunta de pesquisa: de que modo a taxonomia da relação universidade-empresa, elaborada por Bonaccorsi e Piccaluga (1994), adere-se ao contexto das organizações não mercado, quando imersa na realidade dos egressos de Mestrado Profissionais em Administração Pública?

Assim, o objetivo do presente artigo é investigar a aderência da taxonomia de Bonaccorsi e Piccaluga (1994) ao contexto de organizações não mercado. Ao realizar essa investigação, abriu-se espaço para a identificação dos limites e possibilidades da referida obra para análise da inovação, especificamente, em organizações públicas, ensaiando uma possível contribuição para essas instituições.

\section{FUNDAMENTAÇÃO TEÓRICA}

A fundamentação teórica é aquela que dá corpo às pesquisas, fornece a base de sustentação para qualquer investigação científica. Por isso, nesse primeiro momento, é preciso focar termos, conceitos e modelos que sustentem a problemática proposta. Inicialmente, aborda-se o conceito de inovação para, então, alcançar o de Sistema Nacional de Inovação, bem como os demais modelos importantes para a compreensão do tema, principalmente a taxonomia de Bonaccorsi e Piccaluga (1994).

Inovação, genericamente, pode ser conceituada como a evolução de uma invenção, a qual, dentro do contexto organizacional, recebe a adição de sistemas produtivos, mas principalmente que esteja baseada na oferta de novos produtos ou 
serviços aos consumidores capazes de satisfazer suas necessidades e desejos (FIEDLER, 2011). A partir desses aspectos, a inovação tem se tornado ponto central das estratégias organizacionais e também foco de diversos estudos e publicações (NUNES, 2009), principalmente pelo fato de depender mais dos processos de aprendizagem do que da disponibilidade de recursos em si, apesar da notória importância que estes possuem (MOTA, 1999). Desse modo, o processo de aprendizagem tem seu alicerce na busca dos indivíduos pela condição de membro de um grupo de trabalho (prática), considerando fatores técnicos e comportamentais. Portanto, isso conduz à caracterização das organizações como ambientes de construção coletiva de sentidos, significados e geração de conhecimento, induzindo a busca por novas maneiras de compreender os processos de aprendizagem, principalmente aqueles de natureza informal e que fazem parte do cotidiano das pessoas, dos grupos de trabalho e das organizações como um todo (BISPO; GODOY, 2012).

Logo, em virtude dessa condição constante de construções e reconstruções dentro das organizações, emerge a necessidade de um processo de inovação não mais restrito aos limites organizacionais, indo além dessas fronteiras, ou seja, passando de uma atitude fechada, com objetivos internos, para uma atitude aberta, na busca por parceiros externos com o propósito de dividir os riscos, diminuir os custos e obter retornos crescentes com a P\&D (BIGNETTI, 2002). Portanto, esse processo é visto como sistêmico, no qual a organização não é capaz de inovar sozinha, precisando agregar a essa dinâmica outras empresas, fornecedores, concorrentes, clientes ou até mesmo universidades e centros de pesquisa, além de órgãos governamentais, no sentido de "somar forças" para alcançar diferenciais e assim domínio e crescimento econômico (PUFFAL, 2011). Entretanto, não basta estabelecer uma discussão superficial sobre como as organizações geram conhecimento e inovação a partir das interações e do cotidiano. Por isso, é importante alcançar o entendimento da atribuição de significado, da criação de sentidos que ocorrem dentro das organizações e de que maneira tudo se relaciona e contribui para os processos de aprendizagem anteriormente citados como condicionantes para a aplicação da inovação como estratégia (BISPO; GODOY, 2012).

Assim, com base nessa perspectiva, alcança-se o contexto do chamado Sistema Nacional de Inovação (SNI), cuja característica principal é o entrelaçamento entre a ciência e a tecnologia, sendo que a 
primeira envolve os conhecimentos gerados pelo sistema científico, e a segunda tem como responsabilidade a transformação desses conhecimentos em novas tecnologias, aplicáveis e úteis aos ambientes organizacionais (NELSON; ROSENBERG, 1993; $\quad$ SUZIGAN; ALBUQUERQUE; CARIO, 2011). Para que esse avanço científico e tecnológico aconteça, tanto nos países desenvolvidos quanto naqueles em fase de desenvolvimento, há a necessidade da existência de atores principais, os quais já foram citados, mas que merecem destaque, pois cada um faz sua parte individual, gerando resultados no todo (PUFFAL, 2011). Esses atores são as empresas (organizações) em si, com seu conhecimento da tecnologia, em que as "tentativas e erros" levam a avanços, antes de qualquer orientação sistematizada por parte da ciência; as universidades (Instituições de Ensino Superior ou Centros de Pesquisa), com sua pesquisa científica que leva ao embasamento teórico e estabelece uma vinculação palpável entre a tecnologia e a ciência que se torna responsável pela grande intensificação da pesquisa, fundamental para a sustentação da prática; e, por fim, o governo (Estado), como órgão fomentador, o qual garante os recursos necessários para a continuidade desses estudos por meio da educação e dos incentivos financeiros (PUFFAL, 2011;
ROSENBERG, 2006).

A partir disso, o SNI é visto como um "plano de fundo" de estudos que visam averiguar relações entre organizações, regulamentadas por instituições específicas, para a geração de inovação e consequentemente desenvolvimento econômico, o qual pode ser em nível nacional, regional ou local. Portanto, a compreensão do SNI se torna determinante para a identificação dos gargalos e dos pontos de alavancagem para intensificar a atividade inovativa, bem como o desenvolvimento econômico e a competitividade global consequentemente.

A partir de tudo que foi descrito, pode-se dizer que o SNI permite que todos os elementos que fazem parte do contexto inovativo possam ser organizados, estruturados e focados, sem que esforços sejam desperdiçados. No contexto nacional, está clara a deficiência desse sistema, assim é preciso mantê-lo em permanente discussão, mostrando que, se bem alicerçado, todos serão beneficiados, e o desenvolvimento acontecerá em um âmbito muito maior.

O modelo da Hélice Tríplice a ser apresentado demonstra três atores importantes que precisam ser engajados para que a inovação ocorra, colaborando assim com os conceitos vistos sobre o SNI. Esse modelo tem como foco viabilizar a necessária harmonia entre as iniciativas 
dos agentes do desenvolvimento, ou seja, da universidade, das empresas e do governo (PLONSKI, 2007). Seu propósito consiste na geração de conhecimento a partir das relações entre esses três principais participantes do Sistema de Inovação ～～2003; ETZKOWITZ; KLOFSTEN, 2005). Com isso, enfatiza-se que o interesse de cada elo na rede precisa ser observado, lembrandose dos interesses diferentes no processo de transferência tecnológica, do impacto cultural das entidades e dos meios de comunicação adequados (DESIDERIO; ZILBER, 2014).

Segundo Etzkowitz (2002), quando se fala em relação universidade-empresagoverno, podem ser citados três modelos básicos, os quais se diferenciam pelo grau de interação de cada um desses três atores. No primeiro modelo, os agentes são separados, mas tanto a empresa quanto a universidade ficam subordinadas ao governo. Já o segundo descreve uma situação um pouco diferente, na qual se encontram isolados, tal como no anterior, porém sem a existência da relação de subordinação, atuando cada um de forma individual. Finalmente, o último demonstra, literalmente, uma "hélice", em que a função de cada ator se sobrepõe a do outro, construindo uma relação de cooperação.

Observou-se, então, que tanto o modelo da Hélice Tríplice quanto o SNI conduzem para a relação entre as instituições de ensino superior e as organizações, ou, como se encontra na literatura, a "relação universidadeempresa". Percebe-se que todos estão voltados para a propulsão da inovação e da criação permanente de possibilidade para inovar. Porém, não de forma isolada, mas interagindo e realizando trocas entre as experiências práticas das organizações, as teorias das IES, o conhecimento e, até mesmo, os recursos governamentais.

A cooperação entre universidade $\mathrm{e}$ organizações de mercado (empresas), no Brasil, vem sendo investigada como uma opção estratégica para o desenvolvimento de competências necessárias às organizações e de novos conhecimentos para o incremento da capacidade competitiva (GONÇALO; ZANLUCHI, 2011).

A interação universidade-empresa é abordada tanto nas instituições do Sistema Nacional de Inovação como também dentro do Modelo da Hélice Tríplice.Nos dois contextos, essa relação é vista como de grande importância, principalmente, dentro do campo competitivo que as organizações estão vivenciando, vendo-se nas universidades grandes possibilidades na área de P\&D (DAGNINO, 2003; LEYDESDORFF; ETZKOWITZ, 2001). As contribuições das universidades para o 
processo de inovação abrangem desde o conhecimento mais geral necessário para as atividades de pesquisa básica até o mais específico relacionado à determinada área da organização (NELSON, 1990).

A partir de todos esses conceitos, pode-se chegar ao que Bonaccorsi e Piccaluga (1994) propuseram: um modelo teórico, no qual as motivações que levam as organizações a estabelecer relações com as universidades possuem impacto direto em suas expectativas de geração, transmissão e propagação de conhecimento. O desempenho real dessa relação depende da junção das características do processo de transferência do conhecimento e das questões estruturais e processuais da própria relação. Logo, o resultado será mensurado a partir da comparação entre o desempenho esperado e o desempenho real nos termos de geração, transmissão e propagação de conhecimento, podendo ainda ser apontados novos objetivos no decorrer desse processo (BONACCORSI; PICCALUGA, 1994).

Além do modelo teórico apresentado, Bonaccorsi e Piccaluga (1994) construíram uma taxonomia composta por seis tipos de relação universidade-empresa, identificando, como principal variável, os recursos organizacionais envolvidos, tais como pessoal, equipamentos e recursos financeiros de ambas as partes, levando ainda em consideração o prazo de duração e a formalização do acordo (BONACCORSI; PICCALUGA, 1994). São elas: a) relações pessoais informais; b) relações pessoais formais; c) relações com envolvimento de uma terceira instituição; d) acordos formais com definição de objetivos; e) acordos formais sem definição de objetivos; f) criação de estruturas focadas, específicas e permanentes para a interação.

Ao analisar cada um dos casos, Bonaccorsi e Piccaluga (1994) realizaram uma breve descrição e, em seguida, citaram exemplos práticos. Avançando nesse sentido, Puffal (2011) deu sua contribuição que ajudou a esclarecer, por meio de outros exemplos mais próximos do cotidiano do Brasil e das relações vivenciadas nas universidades e organizações desse país, o que as primeiras autoras definiram. Nesse mesmo sentido, ou seja, ilustrar a taxonomia existente juntamente com as contribuições de Puffal (2011), elaborou-se o Quadro 1. 
Quadro 1 - Taxonomia da relação universidade-empresa

\begin{tabular}{|c|c|c|}
\hline Forma & Descrição & Exemplos \\
\hline $\begin{array}{l}\text { a) Relações } \\
\text { Pessoais } \\
\text { Informais }\end{array}$ & $\begin{array}{l}\text { Ocorrem quando há troca de informações } \\
\text { entre a empresa e um indivíduo da } \\
\text { universidade, sem que qualquer acordo } \\
\text { formal que envolva a universidade seja } \\
\text { elaborado. }\end{array}$ & $\begin{array}{l}\text { Consultorias individuais (pagas ou } \\
\text { gratuitas); } \\
\text { Publicação de resultados de pesquisas; } \\
\text { Trocas informais em fóruns e workshops. }\end{array}$ \\
\hline $\begin{array}{l}\text { b) Relações } \\
\text { Pessoais } \\
\text { Formais }\end{array}$ & $\begin{array}{l}\text { Características semelhantes às relações } \\
\text { informais, porém, com acordos ou } \\
\text { convênios formais entre universidade e } \\
\text { empresa. }\end{array}$ & $\begin{array}{l}\text { Bolsas de estudo e apoio à pós-graduação; } \\
\text { Intercâmbio de pessoal entre empresa e } \\
\text { universidade; } \\
\text { Estágio de alunos; } \\
\text { Especialização de trabalhadores das } \\
\text { empresas nas universidades. }\end{array}$ \\
\hline $\begin{array}{l}\text { c) Relações } \\
\text { desenvolvidas } \\
\text { por Instituições } \\
\text { de Ligação ou } \\
\text { Intermediação } \\
\end{array}$ & $\begin{array}{l}\text { Uma terceira instituição estabelece as } \\
\text { relações entre universidade e empresa, } \\
\text { podendo ser interna à universidade, } \\
\text { completamente externa ou em posição de } \\
\text { intermediação. }\end{array}$ & $\begin{array}{l}\text { Associações industriais; } \\
\text { Institutos de pesquisa aplicada; } \\
\text { Unidades assistenciais gerais; } \\
\text { Fundações universitárias. }\end{array}$ \\
\hline $\begin{array}{l}\text { d) Acordos } \\
\text { Formais com } \\
\text { Objetivos } \\
\text { Definidos } \\
\end{array}$ & $\begin{array}{l}\text { São relações em que ocorre a formalização } \\
\text { do acordo e a definição dos objetivos } \\
\text { específicos desse acordo. }\end{array}$ & $\begin{array}{l}\text { Pesquisas contratadas; } \\
\text { Desenvolvimento de protótipos e testes; } \\
\text { Treinamento de trabalhadores; } \\
\text { Projetos de pesquisa cooperativa. }\end{array}$ \\
\hline $\begin{array}{l}\text { e) Acordos } \\
\text { Formais sem } \\
\text { Objetivos } \\
\text { Definidos }\end{array}$ & $\begin{array}{l}\text { Acordos formalizados, como no item d, } \\
\text { mas possuem objetivos estratégicos mais } \\
\text { amplos e de longo prazo. (contrato guarda- } \\
\text { chuva). }\end{array}$ & $\begin{array}{l}\text { Empresas patrocinadoras de P\&D nos } \\
\text { departamentos universitários; } \\
\text { Doações e auxílios para pesquisa de forma } \\
\text { genérica ou para departamentos específicos. }\end{array}$ \\
\hline $\begin{array}{l}\text { f) Criação de } \\
\text { Estruturas } \\
\text { próprias para a } \\
\text { Interação }\end{array}$ & $\begin{array}{l}\text { Relações entre empresa e universidade } \\
\text { realizadas em estruturas permanentes e } \\
\text { específicas criadas para tal propósito. }\end{array}$ & $\begin{array}{l}\text { Parques tecnológicos; } \\
\text { Institutos de pesquisa; } \\
\text { Laboratórios de pesquisa; } \\
\text { Consórcios de pesquisa universidade- } \\
\text { empresa; } \\
\text { Incubadoras tecnológicas. }\end{array}$ \\
\hline
\end{tabular}

Fonte: Bastiani (2014) a partir de Bonaccorsi e Piccaluga (1994) e Puffal (2011).

A partir dessa taxonomia de Bonaccorsi e Piccaluga (1994), é possível afirmar que diversos instrumentos podem ser utilizados para concretizar a cooperação, sendo a escolha dependente da posição e dos objetivos de cada participante frente ao processo, contemplando a maleabilidade e a adequação necessárias ao tipo a ser desenvolvido (SEGATTO-MENDES; SBRAGIA, 2002).

Para compreender a inovação dentro do contexto das organizações não mercado, é importante destacar que existem diferentes formas organizacionais, tais como "de mercado", "públicas" e “associativas" (FRANÇA-FILHO, 2004, p. 141). Na literatura apresentada até o momento, observou-se a predominância do termo "empresa", que leva a compreender que $o$ foco são as relações entre universidades e organizações denominadas por França-Filho (2004) como "de mercado", as quais estão "orientadas segundo uma lógica fundamentalmente econômica e utilitária", além de serem "consideradas como iniciativas privadas" (FRANÇA-FILHO, 2004, p. 141). 
Desse modo, evidencia-se que as organizações caracterizadas como "públicas" e "associativas" parecem não fazer parte. Contudo, tem-se visto uma crescente conexão entre os conceitos do setor social e privado, o que é comprovado pela proliferação dos termos "empresa social" e "inovação social", ou seja, os preceitos aplicados a organizações de mercado estão sendo inseridos no contexto das públicas ou das associativas (FRANÇA-FILHO, 2004; PHILLS; DEIGLMEIER; MILLER, 2008).

Nesse estudo, embora se reconheça que o termo 'pública' não é sinônimo de 'estatal' ou 'governo', a definição de França-Filho (2004) é assumida, entendendo como organizações públicas aquelas que "atuam no espaço chamado Estado, orientando-se segundo a lógica do poder burocrático e devem, por princípio, buscar satisfazer a dignidade dos cidadãos". Já aquelas de natureza associativa têm como campo de atuação o "espaço público da sociedade, isto é, fora de circuito do Estado e do mercado", sendo "consideradas como iniciativas privadas" por partirem da ação de cidadãos, mas sem objetivos lucrativos, almejando o alcance de finalidades que são públicas (FRANÇAFILHO, 2004, p. 141).

Ao delimitar-se esses três tipos distintos de organizações existentes, a partir dos estudos e considerações de
França-Filho (2004), pode-se discorrer sobre a inovação em organizações não mercado. Com isso, observa-se um novo enfoque, diferentemente do que vem sendo mencionado neste apanhado teórico, que, por meio da interpretação, percebeu-se a predominância do cunho econômico e do objetivo competitivo a partir das inovações e das relações interorganizacionais.

Logo, nota-se que os conceitos básicos dessas interações estão constantemente ligados às organizações de mercado voltadas ao lucro (empresas), sendo a maximização desse lucro, minimização dos custos e o avanço tecnológico os resultados provenientes das ações de inovação. Com isso, tanto o governo como as organizações públicas que o alicerçam são apontados apenas como fomentadores do processo inovativo, esquecendo-se do fato de que essas organizações, tais como quaisquer outras, também necessitam de inovação para o aperfeiçoamento de seus processos e, assim, para a satisfação com excelência da dignidade dos cidadãos.

Com isso, a inovação, dentro do contexto público, ganha ênfase de tal modo que os governos neste século estão sendo levados à aplicação de ações criativas e abordagens inovadoras devido a inúmeros desafios enfrentados. Entre estes, encontram-se desde a globalização, o combate à desigualdade e o respeito da 
diversidade, até a busca permanente pela boa governança e por uma gestão pública realmente eficiente (BRANDÃO; BRUNO-FARIA， 2013; SCHWELLA, 2005). Em vista disso, observa-se que o estabelecimento de estratégias é um desafio às habilidades de gestão, especialmente para os modelos de organizações que não têm como foco a lucratividade (BLANCK; JANISSEKMUNIZ, 2014).

Segundo Brandão e Bruno-Faria (2013), existem razões econômicas e sociais que estimulam a inovação do setor público. As econômicas abrangem, primeiramente, o fato de o setor público contribuir com parcela significativa do PIB (entre 20 e 50\%) de sua nação; ser responsável por prover serviços para cidadãos e empresas, sendo a inovação um apoio para o alcance de melhores resultados; e, por fim, levando em consideração os sistemas nacionais de inovação, já que é sua responsabilidade a definição das políticas de fomento à inovação no setor privado, nada melhor do que promover internamente a inovação (POTTS; KASTELLS, 2010 apud BRANDÃO; BRUNO-FARIA, 2013). Sob a perspectiva social, quando um setor público se torna inovador, disponibiliza produtos e serviços de boa qualidade, o que conduz a uma relação mais eficaz com os cidadãos (BRANDÃO; BRUNO-
FARIA, 2013).

Embora, a partir de uma visão genérica, similaridades possam ser encontradas entre o ambiente do setor público e o privado, existem diferenças significativas quando comparados aspectos, principalmente, relacionados às características dos serviços oferecidos ao processo de tomada de decisão, à estrutura organizacional, às condições gerais, aos objetivos e ao processo como um todo. Isso demonstra que, apesar de semelhanças serem encontradas, no geral, quando detalhado, o modelo de medição precisará ser necessariamente diferente para conseguir as especificidades exigidas pela inovação no setor público (BLOCH, 2010). Em consequência dessas peculiaridades, Bloch (2010) estruturou uma tipologia da inovação no setor público, a qual determina a existência de quatro tipos específicos, tal como se apresenta no Quadro 2. 
Quadro 2 - Tipos de Inovação no Setor Público

\begin{tabular}{|l|l|}
\hline \multicolumn{1}{|c|}{ Tipos de inovação } & \multicolumn{1}{c|}{ Definição } \\
\hline Inovação de Produto & $\begin{array}{l}\text { Introdução de serviço ou de bem novo, ou significativamente melhorado, } \\
\text { quando comparado com os serviços e bens já existentes na organização. }\end{array}$ \\
\hline Inovação de Processo & $\begin{array}{l}\text { Implementação de método de produção ou de entrega de serviços ou de bens } \\
\text { novos, ou significativamente melhorados, quando comparados com os processos } \\
\text { já existentes na organização. }\end{array}$ \\
\hline Inovação Organizacional & $\begin{array}{l}\text { Implementação de novo método organizacional ou gerencial que difere } \\
\text { significativamente dos já existentes na organização. }\end{array}$ \\
\hline Inovação em Comunicação & $\begin{array}{l}\text { Implementação de novo método de promoção da organização ou de seus } \\
\text { serviços e bens, ou de novos métodos para influenciar o comportamento de } \\
\text { indivíduos ou de outras organizações. }\end{array}$ \\
\hline
\end{tabular}

Fonte: Bloch (2010).

Observa-se, nessa tipologia, que Bloch (2010) fez uso do termo "Inovação de Produto", porém a maioria dos estudiosos dessa área costuma empregar "Inovação de Serviços". Isso pode estar relacionado ao fato de as inovações, no contexto público, resultarem, na maioria dos casos, em novos serviços. Logo, percebe-se que a inovação em serviço é um dos principais tipos de inovação estudados, juntamente com a inovação em processos, podendo ser incluídas as inovações em estruturas e em sistemas administrativos, bem como as inovações de cunho tecnológico (BRANDÃO; BRUNOFARIA, 2013; VARGAS, 2010).

Nesse sentido, a administração pública se transforma em uma agência prestadora de serviços com foco na transparência, na responsabilidade e nas necessidades da sociedade, buscando um resultado perceptível de como os cidadãos possam ser inseridos no processo por meio da democratização ao acesso à informação. Assim se caracteriza o modelo das gestões públicas que pensam de forma inovadora (BARRACHINI, 2002; FREITAS; DACORSO, 2014).

Observa-se, dessa forma, que o papel do estado mudou, passando de financiador da produção para incentivador da inovação como estratégia. Conhecedores dessa mudança, estudiosos das ciências sociais criticam o "predomínio da racionalidade funcional nas teorias utilizadas para o planejamento e análise de sistemas sociais, ajudando, dessa forma, a apontar as lacunas existentes para dar conta da sociedade complexa" (DIAS; CARIO, 2014, p. 373).

Logo, isso permitirá a estruturação de um sistema político multidimensional que sirva à sociedade, perpassando os interesses econômicos, enfraquecendo a visão funcionalista predominante na sociedade e nos estudos da área das Ciências Sociais. Percebe-se, portanto, o Estado como agente estratégico fundamental no sentido de manter integradas as dimensões econômica e 
social, garantindo os serviços sociais essenciais (DIAS; CARIO, 2014).

A partir disso, pode-se dizer que o processo de inovação no setor público tem tomado caminhos diferentes dos exercidos no passado, principalmente pelo fato de as estratégias de inovação das organizações privadas estarem, cada vez mais, sendo incorporadas na administração pública brasileira, sendo que "a principal prática inovadora foi no sentido de ressaltar que o contribuinte não é um súdito do Estado, mas um cliente com direito à boa prestação de serviços públicos". E, ainda, após a promulgação da Constituição de 1988 no Brasil, ocorreram pressões da sociedade civil, ou seja, das organizações chamadas, por França-Filho (2004), como "associativas", agora mais ativas e organizadas, que permitem que novos espaços públicos e de interação sejam criados, passando a disseminar, então, os conceitos de inovação para o campo das públicas (FREITAS; DACORSO, 2014; JACOBI; PINHO, 2006).

O setor público, em função de sua natureza complexa, precisa promover inovações concretas que conduzam a efetivas transformações, as quais enfatizem que o pressuposto mais adequado para a gestão pública é a associação do conceito de inovação à perspectiva de transformação. Dessa maneira, a inovação no setor público passa ser definida como "uma mudança de cunho radical que se justifica por fins estratégico, estrutural, humano, tecnológico, cultural, político e de controle" (KLERING; ANDRADE, 2006).

É oportuno também mencionar que, apesar de a autoria e de o grau de novidade estarem geralmente contemplados nas definições de inovação, tanto no contexto privado quanto no público, um tende a valorizar mais um aspecto do que outro. Então se observa que o privado costuma considerar mais inovações que se mostram como inéditas, enquanto o público adota mais frequentemente inovações geradas em outras organizações. Porém, isso não implica em classificar um setor como mais ou menos inovador do que o outro (BRANDÃO; BRUNO-FARIA, 2013).

\section{PROCEDIMENTOS METODOLÓGICOS}

A pesquisa aqui apresentada, tendo como base a classificação de Morgan, pode ser enquadrada como interpretativista pelo fato de tentar entender os processos pelos quais as múltiplas realidades compartilhadas surgem, são sustentadas e se modificam (MORGAN, 2005).

Já que o objetivo desta pesquisa passa a colaborar com a construção do conhecimento sobre inovação, cabe lembrar a reflexão realizada por Dias (2012), embasada nos estudos de Morin (1996), que indicam que nenhuma ciência deve ser tida como absoluta. Sendo assim, 
uma teoria científica acaba absorvendo aspectos incertos, o que leva a ser compreendida como algo inacabado. É com essa perspectiva que todo o estudo aqui apresentado se desenvolveu, ou seja, fomentando reflexões que surgiram durante o processo de busca por uma resposta à pergunta de pesquisa proposta. Isso, contudo, consciente de que, para haver avanços, construções ou reconstruções do conhecimento existente, é preciso entender que "conhecer é uma aventura incerta, frágil, difícil, trágica" (MORIN, 1996, p. 33). Portanto, se é uma aventura, como alerta Dias (2012, p. 192), "reserva surpresas".

De acordo com os conceitos anteriores, esta pesquisa ainda enquadra-se como do tipo survey ou de levantamento, possui também uma abordagem predominantemente qualitativa, embora existam aspectos que dificultem o encaixe de forma clara de uma pesquisa nessa abordagem. Dessa forma, a escolha predominantemente qualitativa se justifica, sobretudo, por ser a mais adequada para compreender a natureza dos fenômenos sociais, mostrando que não se pretende numerar ou medir unidades ou categorias homogêneas (CRESWELL, 2007; RICHARDSON, 2008; TRIVIÑOS, 2011).

Com isso, é notório que essa abordagem está sim comprometida com a construção de estudos realmente confiáveis e sujeitos à aprovação nos processos de avaliação, construindo, dessa forma, fontes realmente confiáveis de pesquisa científica, rompendo, de fato, as dicotomias com a abordagem quantitativa (TRIVIÑOS, 2011). Dicotomias que, na realidade, como alertou Vieira (2006), não existem, insurgindo apenas da obstinação dos pesquisadores em defender a qualitativa ou a quantitativa. A partir dessa perspectiva, neste estudo há certa dificuldade em delimitar a dicotomia, por isso a característica predominantemente qualitativa é ratificada.

Observa-se ainda que a pesquisa apresentada necessitou de técnicas derivadas da abordagem quantitativa para o levantamento de dados essenciais para conhecer a realidade que se pretende estudar. Assim, fica evidente que a pesquisa também se enquadra como descritiva. Finalmente, pode-se dizer que a pesquisa aqui relatada, de acordo com o seu horizonte de tempo, é conceituada como transversal, tendo em vista que a coleta de dados ocorreu em um só período de tempo.

Após os enquadramentos, segundo os paradigmas e a abordagem de pesquisa, busca-se apresentar o percurso realizado para a construção deste estudo. Como campo de pesquisa, foram delimitados quatro programas de mestrados profissionais. Para chegar a essa 
delimitação, primeiramente realizou-se consulta ao site da Coordenação de Aperfeiçoamento de Pessoal de Nível Superior (CAPES) em busca da Planilha de Indicadores referente ao triênio 2010-2013 de avaliação dessa coordenação. Após acessar a planilha de avaliação de 2013 da área de Administração, Ciências Contábeis e Turismo, identificaram-se todos os programas em que havia em sua nomenclatura como primeiro termo “Administração". Desses selecionados, separaram-se todos na modalidade profissional, em seguida realizou-se, no site das IES, a busca das linhas de pesquisa de cada uma. Com isso, mais um corte se fez naqueles que tivessem em suas linhas de pesquisa ou mesmo em sua nomenclatura temas ligados à Administração Pública e também naqueles que obtiveram conceito 4 ou superior no referido triênio de Avaliação da CAPES. Desse modo, para efetivação desse corte, foram utilizados três critérios, ou seja, as linhas de pesquisa e nomenclatura dos programas, bem como seu conceito no último triênio de avaliação da CAPES.

Assim, nota-se que a técnica de seleção da amostra aplicada foi a por conveniência, a qual, embora não possua qualquer controle explícito, pode tornar-se útil para testar ideias ou aspectos de um assunto de interesse, sendo que pode também resultar em evidências de grande relevância, tornando desnecessários procedimentos de amostragem mais sofisticados (COOPER; SCHINDLER, 2003), envolvendo, no caso apresentado, características específicas para que os indivíduos façam parte da amostra final, cabendo ao pesquisador a avaliação e o enquadramento do indivíduo.

A partir da base teórica que sustenta a taxonomia de Bonaccorsi e Piccaluga (1994), principalmente dos exemplos mencionados, partiu-se para a construção do instrumento de coleta de dados primários, que foi um questionário composto por três blocos de questões. $\mathrm{O}$ Bloco "A" objetivava conhecer o perfil acadêmico dos alunos-pesquisadores (egressos), pertencentes à amostra, em termos da escolha do programa de mestrado, bem como a linha de pesquisa optada para o desenvolvimento de sua dissertação, além de seus propósitos a partir da obtenção do título de mestre. $\mathrm{O}$ Bloco "B" visava caracterizar o perfil profissional dos egressos, no que tange à organização de atuação profissional, se esta foi o objeto de pesquisa para a construção de sua dissertação e, ainda, como se classificava (Mercado, Pública ou Associativa). Por fim, o Bloco "C" se propunha a apontar o perfil da relação universidade-empresa que pudesse ser evidenciado na pesquisa para desenvolvimento da dissertação dos 
egressos respondentes, especialmente aqueles em que o campo de estudo delimitou como a mesma organização de atuação profissional.

Depois de construído o instrumento de coleta de dados, foi reestruturado dentro da ferramenta on-line Google Docs, que, apesar de possuir algumas limitações, possibilita a divulgação do questionário via link de acesso. Desse modo, com o questionário pronto, cada um dos programas foi contatado via e-mail e telefone, solicitando o contato de seus alunos egressos a partir de 2011. Contudo, como as IES possuem em suas normativas a impossibilidade de divulgar esses contatos, o link com o questionário e informações sobre a pesquisa foram encaminhados às coordenações para divulgar entre seus egressos que haviam defendido a dissertação a partir de 2011.

Concluído o período de coleta de dados via questionário, que foi de junho a agosto/2014, foram obtidas 21 respostas de um universo de 128 egressos, pertencentes a quatro instituições de ensino superior distribuídas nas regiões Sul, Sudeste, Centro-Oeste e Nordeste do Brasil, mais especificamente ex-alunos dos mestrados profissionais em Administração Pública da Universidade do Estado de Santa Catarina (UDESC), Fundação Getúlio Vargas do Rio de Janeiro (FGV/RJ), Universidade de Brasília (UnB) e Universidade Federal da
Bahia (UFBA). Sendo assim, a pesquisa contou com dados primários, levantados a partir dos questionários e, também, com dados secundários, esses já estruturados pela CAPES e presentes nos sites das IES.

Uma vez organizados os dados, a análise foi realizada a partir da comparação da teoria e da prática, entendendo que cada um dos tipos de relação universidadeempresa (Quadro 1), presentes na taxonomia de Bonaccorsi e Piccaluga (1994), constitui-se como uma categoria de análise, a saber: a) relações pessoais informais; b) relações pessoais formais; c) relações com envolvimento de uma terceira instituição; d) acordos formais com definição de objetivos; e) acordos formais sem definição de objetivos; f) criação de estruturas focadas, específicas e permanentes para a interação.

\section{ANÁLISE DOS RESULTADOS}

$$
\text { Para a efetivação da presente }
$$
análise dos resultados, é necessária a conexão com a teoria que oferece a taxonomia da relação universidadeempresa proposta por Bonaccorsi e Piccaluga (1994). Como já mencionado na fundamentação teórica, essa taxonomia tem como critérios de categorização a relação universidade-empresa ser ou não intermediada por instituições; ser apenas fundamentada na união de parques tecnológicos; ser formal ou informal 
(BONACCORSI; PICCALUGA, 1994).

Além do embasamento teórico, é importante recordar o objetivo que norteia este estudo, ou seja, "analisar a taxonomia da relação universidade-empresa quando aplicada às organizações não mercado, a partir da perspectiva dos egressos de mestrados profissionais em Administração Pública que delimitaram como campo de pesquisa para a sua dissertação as organizações em que atuavam profissionalmente".

Inicia-se essa análise relacionando o perfil acadêmico, o perfil profissional e a organização campo de pesquisa dos egressos pertencentes à amostra. Essa relação se torna evidente quando observadas as razões elencadas pelos egressos que levaram à escolha do programa de mestrado, de sua modalidade, do tema para a dissertação e do objetivo com o título de mestre, sendo todos focados na organização na qual atuavam profissionalmente. Esse fato se torna ainda mais nítido quando as organizações campo de pesquisa são caracterizadas como públicas, já que as linhas de pesquisa dos programas elencados estão voltadas para a Administração Pública.

O que é estruturado com essa relação é o aspecto inicial que norteou esta pesquisa, ou seja, alunos-pesquisadores que utilizam seus locais de trabalho como base empírica, mostrando ainda, a partir dos resultados, que essas organizações são fatores impulsionadores para iniciar essa qualificação. Por fim, dentro do campo da Administração, isso precisa ser mais bem analisado, por mais que ainda não se tenha entrado na questão da relação universidade-empresa. A conexão entre essas duas instituições ocorre de maneira frequente e mediada pelos alunos, pois precisam das organizações, independentemente de sua modalidade, para estudar os embasamentos teóricos existentes, para tornar permanente a construção e reconstrução do conhecimento. Além disso, o contexto pode alterar as teorias, já que a maioria delas, dentro desse campo, emergiu em países desenvolvidos, assim, é importante trazê-las para o contexto nacional, testá-las e fazer os ajustes pertinentes para ser realmente aplicável.

\subsection{Investigação da aderência da} taxonomia de Bonaccorsi e Piccaluga (1994) ao contexto de organizações não mercado, aplicando-a a amostra selecionada

Para a investigação da aderência da taxonomia selecionada ao contexto de organizações não mercado, mais especificamente as públicas, já que as organizações campo de pesquisa dos alunos-pesquisadores foram caracterizadas dessa forma, foi necessária a construção de 
figuras. Nestas, agruparam-se respostas similares, que continham a quantidade de respondentes que escolheu cada alternativa, para então se fazer a comparação com os tipos descritos na taxonomia da relação universidadeempresa escolhida para estudo.

A primeira análise efetuada partiu de 14 dos 21 respondentes, já que estes é que desenvolveram suas dissertações nas organizações em que atuavam profissionalmente, dos quais 11 ajudaram algum colega, grupo de trabalho ou projeto a partir dos conhecimentos adquiridos no mestrado. Desses 14 iniciais, 10, além de ajudar, também compartilharam os resultados com os membros da organização e, dentre eles, seis também realizaram esse compartilhamento por meio de um evento. Como houve três respostas positivas, podese, inicialmente, enquadrar essa relação como "Pessoal Informal", na qual o contato se realizou entre o aluno egresso, atuando como pesquisador, e a organização sem a presença efetiva e clara da IES. Há também o caso oposto, no qual todas as respostas foram negativas, por isso $\mathrm{o}$ enquadramento não pode ser efetivado, pois é preciso mais informações para encontrar o tipo mais adequado.

Nos demais casos, houve pelo menos uma resposta positiva, o que leva o enquadramento inicial como "Relação Pessoal Informal", mas que pode ser alterado, conforme os demais resultados encontrados com as próximas respostas, tal como qualquer enquadramento inicial realizado. Desse modo, nessa primeira etapa da análise, encontram-se 13 casos enquadrados como "Relações Pessoais Informais" e um caso ainda não definido.

A partir do prévio enquadramento realizado, a análise pode ser continuada, partindo para as respostas referentes à formalização de algum documento pelos três indivíduos envolvidos na relação, ou seja, o egresso como pesquisador para a construção de sua dissertação, a organização como campo de estudo e a IES. Cabe ressaltar que na taxonomia da relação universidade-empresa, proposta por Bonaccorsi e Piccaluga (1994), não se encontra de maneira específica como se dá essa formalização da relação. Com isso, para essas análises, consideraram-se como ferramentas de formalização qualquer tipo de autorização, solicitação, contrato ou convênio emitido para o desenvolvimento da pesquisa na organização. Encontraramse sete respostas negativas para a questão, as quais levam a manter o primeiro enquadramento efetuado, ou seja, "Relação Pessoal Informal".

Porém, para aqueles em que não houve um enquadramento possível, ou seja, em apenas um caso, com a afirmação da emissão de um documento assinado entre as três partes (egresso, IES e 
organização), pode-se conduzir ao tipo "Relação Pessoal Formal”. Porém, como os três estão envolvidos, é oportuno deixar sem enquadramento definido para mais análises, da mesma forma serão deixados os três casos de "Relação Pessoal Informal", em que o documento envolveu apenas o egresso e a organização, e um caso também classificado dessa maneira, porém que envolve os três atores. Há ainda dois casos em que houve assinatura de um documento diretamente entre a IES e a organização, transformando a relação anteriormente tida como informal em uma “Relação Pessoal Formal”, a qual, segundo a literatura, é caracterizada de forma semelhante à "Relação Pessoal Informal", porém, há a presença de acordos ou convênios formais entre a IES e a organização.

Logo, o panorama de enquadramentos foi alterado, havendo sete casos de "Relações Pessoais Informais", dois de "Relações Pessoais Formais" e cinco casos sem enquadramento definido, dentre os quais quatro eram caracterizados como informais, contudo devido ao fato de os documentos firmados serem entre os egressos e as organizações de forma direta ou entre os três atores, optou-se pela não definição. Isso também ocorreu com um caso que já não havia sido enquadrado, o qual, por envolver os três atores, permaneceu sem caracterização específica.
Com essa nova distribuição dos casos, conforme a taxonomia presente na teoria, o próximo passo busca saber se algum tipo de apoio foi fornecido pela organização para realização da pesquisa, para a construção das dissertações dos egressos (bolsa de estudos para cursar o mestrado). Observou-se que três, dos sete casos, que foram anteriormente descritos como "Relações Pessoais Informais", mas que receberam algum tipo de apoio da organização, a qual firmou um contrato para esse apoio diretamente com a IES, transformaram-se em "Relações Pessoais Formais" pelo fato de ter havido o contato formalizado entre as duas instituições envolvidas (IES e organização) sem o envolvimento do aluno. Ainda dentro dos casos classificados como informais, houve um que não recebeu apoio, desse modo o primeiro enquadramento foi mantido. Contudo, em três casos, ainda entre esses informais, o apoio veio decorrente de contratos firmados entre o egresso e a organização, ou ainda entre os três atores, o que novamente gerou um não enquadramento específico para permitir maiores análises.

Já para as duas relações tidas como formais, quando ocorreu o apoio por meio de contrato ou convênio firmado diretamente entre a IES e a organização, ou ainda não houve recebimento de apoio, o enquadramento foi mantido "Relação 
Pessoal Formal". Nos cinco casos antes não identificados, quando aconteceu o apoio por meio do contrato ou convênio direto com as duas instituições, a relação foi definida como "Pessoal Formal". Porém, quando firmado entre os três atores, o não enquadramento se manteve. Ao final, portanto, o enquadramento permaneceu aberto para dois casos em que a relação foi estabelecida entre o egresso e a organização de forma direta e para outros três casos com relações estabelecidas entre o egresso, a IES e a organização, abrangendo ainda um caso de "Relação Pessoal Informal" e oito classificados como "Relações Pessoais Formais".

Complementando a análise, as próximas características descritas confirmam a presença de apenas uma "Relação Pessoal Informal", oito "Relações Pessoais Formais", permanecendo, ainda, sem um enquadramento definido duas relações entre o egresso e a organização de forma direta e outras três firmadas entre $o$ egresso, a organização e a IES, tal como já havia acontecido.

Para tentar sanar os apontamentos não enquadrados, buscou-se saber se uma possível relação de estágio poderia ter sido estabelecida para a construção da dissertação do egresso. Houve apenas um egresso que afirmou, de forma positiva, que suas atuações se caracterizaram como estágio, sendo firmado um termo de compromisso entre os três atores, ou seja, egresso, IES e organização, havendo, com isso, a confirmação de uma "Relação Pessoal Formal”, que já havia sido categorizada. Para os demais respondentes, não houve alteração no enquadramento estabelecido anteriormente. Portanto, os casos não enquadrados permanecem.

Os próximos resultados se referem a outros dois tipos de relação universidadeempresa presentes na taxonomia estudada: uma alicerçada por acordos formais com objetivos definidos; e outra também realizada por meio de acordos formais, porém sem objetivos definidos, comumente chamados de "contratos guarda-chuva". Para tornar possível a análise das respostas, é importante perceber se o acordo firmado tem ligação com a pesquisa do egresso. Caso contrário, observa-se que a relação permanece como anteriormente caracterizada. Esse raciocínio é importante, pois se nada tem a ver com a pesquisa do aluno-pesquisador (egresso), caracteriza-se como relação universidade-empresa, porém, está fora do campo delimitado para a realização deste estudo.

Ao se destacar os aspectos provenientes do caso categorizado como "Relação Pessoal Informal”, tal como "não ter conhecimento sobre fato" de convênios ou contratos, manteve-se como "Relação 
Pessoal Informal". Em relação aos oito casos anteriormente enquadrados como "Relações Pessoais Formais", apenas um mudou de categorização, passando para "Acordo Formal tipo sem objetivos definidos (guarda-chuva)", já que houve um contrato desse tipo assinado entre a IES e a organização, estando ligado à pesquisa do egresso. Voltando-se agora para os cinco casos sem enquadramento definido, mesmo havendo a adição de informações sobre convênios ou contratos, nenhum deles pode ser esclarecido, permanecendo como sem categorização específica.

A partir daqui é preciso retomar a taxonomia de Bonaccorsi e Piccaluga (1994), lembrando que se tem como foco a relação estabelecida entre a IES (universidade) e a organização (empresa), ou seja, a relação deve se dar entre essas instituições. Portanto, nos dois casos em que a formalização ocorreu entre o egresso e a organização de forma direta, observouse a inexistência de envolvimento direto da universidade, o que leva ao enquadramento como "Relação Pessoal Informal", pois a relação da organização com a IES está informal, sem assinatura de nenhum documento (autorização, solicitação, contrato ou convênio).

No que se refere à relação estabelecida entre os três atores, o egresso, a IES e a organização, encontrada em três casos durante a pesquisa, ao se verificar a taxonomia selecionada, não há nenhum tipo que descreva a formalização da relação entre os três, mencionando-se apenas a intermediação de uma terceira instituição facilitadora da relação. Contudo, em virtude da formalidade existente entre a IES e a organização de forma direta, apesar da presença do egresso, foi possível enquadrá-la como uma "Relação Pessoal Formal”.

Com isso, observa-se que na amostra analisada estão presentes três relações enquadradas como pessoais informais, nas quais o contato é direto entre o aluno-pesquisador e a organização, sem que ocorra o envolvimento da IES. Porém, podendo haver ou não a formalização entre o egresso e a organização. Em contrapartida, identificaram-se dez relações pessoais formais, sendo que em algum momento houve a formalização da relação da IES e da organização para a construção da pesquisa da dissertação do egresso, ou por meio de bolsa de estudo, ou por autorização emitida pela IES e deferida pela organização, ou ainda pela assinatura de termo de compromisso de estágio. E, por fim, apenas uma foi enquadrada como acordo formal do tipo sem objetivos definidos, já que ocorreu a formalização de um acordo nessa modalidade entre a IES e a organização, estando ligado à pesquisa desenvolvida pelo egresso. A figura 1 
demonstra o enquadramento final.

Figura 1 - Enquadramento final das relações universidade empresa evidenciadas

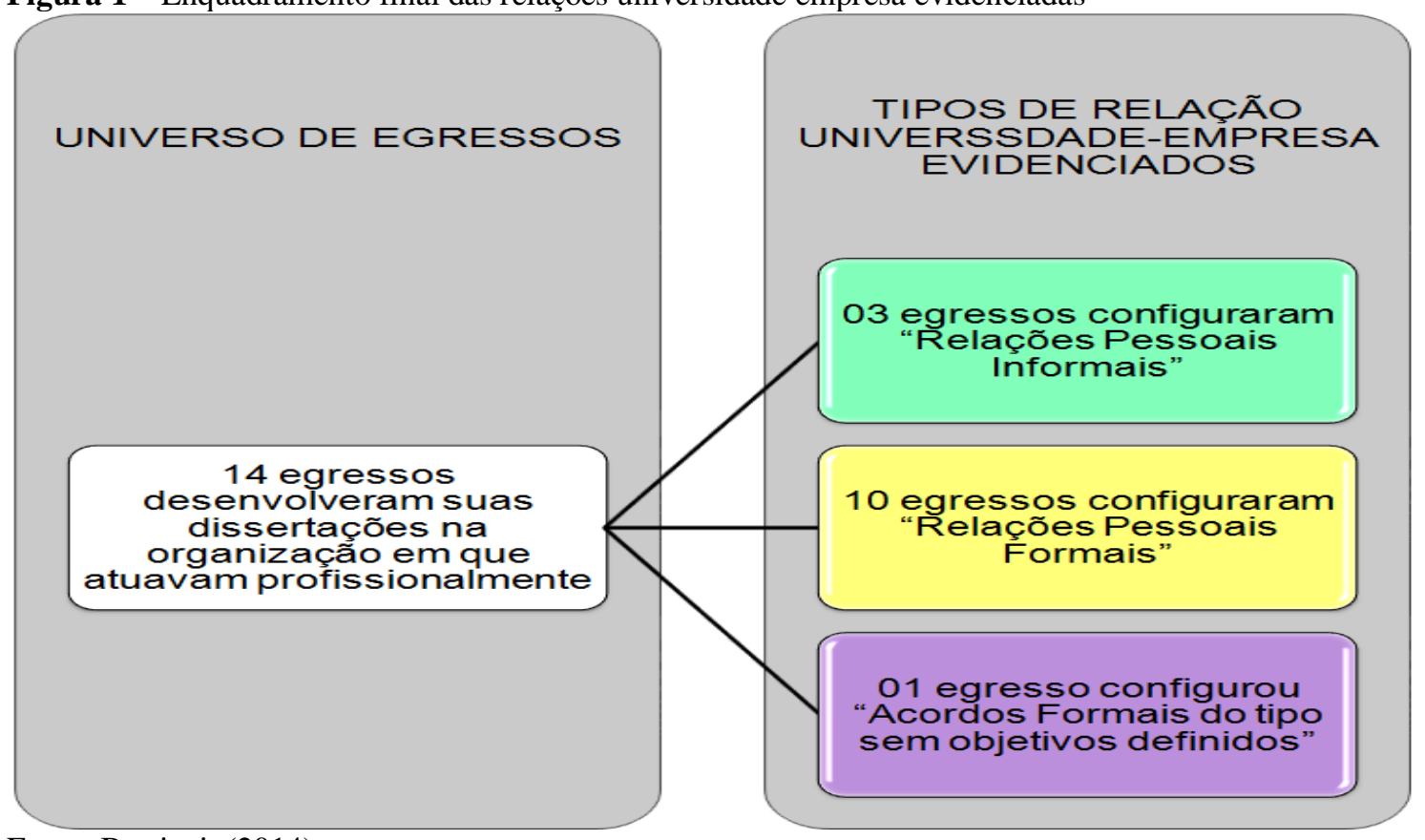

Fonte: Bastiani, (2014).

\subsection{Limites e possibilidades da obra de} Bonaccorsi e Piccaluga (1994) para análise da inovação em organizações públicas

De acordo com os resultados evidenciados, foi possível observar que a relação universidade-empresa, a partir da perspectiva dos alunos egressos de Mestrados Profissionais em Administração Pública que desenvolveram suas dissertações na mesma organização na qual atuavam profissionalmente, pode ser enquadrada em pelos menos três tipos presentes na taxonomia proposta por Bonaccorsi e Piccaluga (1994), dependendo de como cada uma se configura no decorrer do processo de pesquisa dos egressos. Além disso, observou-se que essa taxonomia possui limitações, realizando o enquadramento de alguns casos por meio de interpretação, principalmente a questão das trocas de informações diretas entre o alunopesquisador e a organização, se são apenas formais ou também informais, podendo acontecer até mesmo pela aprendizagem do aluno, o qual leva para seu local de trabalho contribuições informais e até mesmo inconscientes refletidas no aperfeiçoamento de suas atividades cotidianas.

Desse modo, tal como já se pode observar, a referida taxonomia necessita de aprimoramento para que possa abranger organizações diferentes daquelas com cunho econômico, ou seja, as chamadas 
"empresas" ou "de mercado". Como existem "diferentes formas organizacionais", tais como "de mercado", "públicas" e "associativas" (FRANÇAFILHO, 2004, p. 141), evidencia-se que as organizações caracterizadas como "públicas" parecem não fazer parte dessa taxonomia existente. Contudo, tem-se visto uma crescente conexão entre os conceitos do setor social e privado, o que é comprovado pela proliferação dos termos “empresa social” e "inovação social", ou seja, os preceitos aplicados a organizações de mercado estão sendo inseridos no contexto das públicas (FRANÇA-FILHO, 2004; PHILLS; DEIGLMEIER; MILLER, 2008).

Para tanto, é preciso partir do próprio título da referida taxonomia, o qual faz uso do termo "empresa", o que leva à interpretação de que apenas considera organizações com objetivos lucrativos. É importante destacar que as relações entre as IES e as organizações têm como alicerce a inovação como estratégia. Desse modo, observa-se que as organizações públicas também precisam inovar, deixando de atuar somente como fomentadoras do processo.

Observa-se, também, a necessidade de esclarecer como o seu primeiro tipo, "Relações Pessoais Informais", é estruturado, principalmente no que tange ao indivíduo da universidade que troca informações com a organização, devendo assim o contato ser direto entre esse indivíduo e a organização, sem o envolvimento formal da IES. A questão, portanto, ganha destaque quando se questiona se esse indivíduo já é um titulado (mestre ou doutor) ou se pode ser também um aluno de qualquer nível que busca as organizações como campo de pesquisa para seus trabalhos finais, ou até mesmo se pode ser um funcionário da organização que está buscando aperfeiçoamento, realizando um curso na IES.

Ao se destacar-se ainda a presença do aluno ou do egresso, observa-se que a taxonomia faz menção da mediação realizada por outras instituições internas ou externas à IES (Relações desenvolvidas por Instituições de ligação ou intermediação), mas não menciona a intermediação realizada por um indivíduo. Nesse caso, ao se considerar o aluno como indutor da relação entre a IES e a organização, por delimitar como campo de suas pesquisas acadêmicas as organizações, ou ainda, por atuar profissionalmente nessas organizações juntamente com a pesquisa, leva-se a troca contínua e até mesmo imperceptível de conhecimentos teóricos e empíricos.

Em relação ao segundo tipo, "Relações Pessoais Formais", é importante descrever como se dá a formalização da relação entre a IES e a organização, pois, 
do modo que está descrito, parece que qualquer ferramenta de formalização pode ser empregada, tais como autorizações ou solicitações para realização de pesquisas acadêmicas por mestrandos ou doutorandos, ou ainda contratos ou convênios estruturados de tal forma que estejam explícitos os deveres e direitos de cada uma das partes. Esse aspecto surgiu, pois os dados coletados estão baseados na perspectiva de egressos de mestrados profissionais e que fizeram a organização em que atuavam profissionalmente o campo de estudo para a elaboração de sua dissertação, levando, em alguns casos, a assinatura de documentos simples entre as instituições envolvidas, apenas para registrar a execução da pesquisa.

Outro aspecto a ser considerado é a comparação entre as "Relações Pessoais Formais" com os "Acordos Formais com Objetivos Definidos" e com os "Acordos Formais sem Objetivos Definidos". Percebe-se, primeiramente, com base nas nomenclaturas, a característica de formalização das relações entre as IES e as organizações. Contudo, quando comparadas às descrições de cada um desses tipos, as quais podem ser observadas no Quadro 1, apresentado na fundamentação teórica, nota-se que nos três casos as relações ocorrem por meio da formalização de acordos, o que fica duvidoso é como se diferem esses acordos.
Com base na análise dos exemplos presentes em cada um dos tipos, podem-se verificar as diferenças, mas isso não está inserido na descrição, o que acaba dificultando os enquadramentos. Já os demais tipos existentes demonstram limitações voltadas, especialmente, aos termos empregados, tal como já foi descrito.

Logo, ao se considerar a taxonomia como um todo e as teorias e modelos sobre a relação universidade-empresa, observa-se como outro limitador o conhecimento de como ficariam estruturadas as relações quando as organizações que estabelecessem a relação com as IES fossem não empresa, principalmente os exemplos citados na taxonomia. Contudo, assim como levantamentos bibliométricos demonstram, a produção científica sobre inovação no setor público ainda se encontra limitada, sendo oportuno o desenvolvimento de mais conhecimento nessa linha, principalmente no que tange ao processo de inovação; aos determinantes, indutores, facilitadores e barreiras; à liderança; aos efeitos; à disseminação (BRANDÃO; BRUNOFARIA, 2013; LIMA; VARGAS, 2012); e ainda ao desenvolvimento de mais teorias que embasem as relação com organizações não mercado para a implementação da inovação como estratégia, tanto nos produtos e serviços quanto nas 
comunicações e na gestão.

Ao se realizar ainda uma análise dos termos empregados na estruturação da taxonomia em estudo, verifica-se o emprego de "universidade". Contudo, universidade é uma das categorias de instituições de ensino superior (IES) existentes, podendo abranger ainda centros universitários, faculdades e institutos federais (MEC, 2014; MRE, 2014). Por mais que essas modalidades de IES não estejam voltadas para o desenvolvimento da pós-graduação ou ainda focadas, além do superior, no ensino técnico juntamente com o médio, podem também ser vistas como celeiros de desenvolvimento e ampliação da estratégia da inovação, o que não pode ser deixado de lado, ao restringir apenas esse processo às universidades.

\section{CONSIDERAÇÕES FINAIS}

A partir das limitações e possibilidades apontadas, é possível ensaiar adequações à taxonomia de Bonaccorsi e Piccaluga (1994) para que possa vir a ser aplicável também às organizações não mercado. Portanto, observa-se ser oportuna a reestruturação de seu título, bem como de toda descrição dos tipos que a compõem, substituindo o termo "empresa" por "organização", o que mostra o seu compromisso com organizações não econômicas. Ainda é possível estender essa contribuição para a
Teoria da Relação Universidade-empresa como um todo, bem como aos demais modelos empregados nesse contexto, tais como o da Hélice Tríplice e o do Sistema Nacional de Inovação, mencionados na fundação teórica.

Outra alteração de termo a ser sugerida é "universidade" por "Instituição de Ensino Superior" ou sua sigla "IES", para que sejam inclusas as demais categorias existentes, por mais que o fator inovação prevaleça nas universidades devido ao seu caráter obrigatório de desenvolvimento de pós-graduação e execução de pesquisa. Em relação a cada um dos tipos elencados na taxonomia, é importante não apenas expor exemplos para explicá-los, mas também trazer em sua descrição mais elementos que possam conduzir a compreensão de como cada um se estrutura especificamente, sobretudo aqueles com caráter formal.

Nesse sentido, considerando as mudanças dos termos "empresa" e "universidade", é conveniente a realização de pesquisas para encontrar exemplos práticos que ilustrem as relações entre organizações não mercado (públicas ou associativas) e outros tipos de IES (centros universitários, faculdades, institutos federais).

Além disso, é importante, na apresentação dessa taxonomia, discorrer sobre o que pode ser considerado algo 
"formal" e "informal", pois, conforme o contexto, podem adquirir significados variados, principalmente determinando se uma relação só será formal apenas quando considerados documentos mais complexos, tais como contratos, convênios ou acordos, ou se simples formulários de solicitação e autorização são suficientes para tanto. Dessa forma, as limitações relacionadas às "Relações Pessoais Formais" e aos "Acordos Formais com ou sem Objetivos Definidos" ficariam esclarecidas.

Sugere-se, para o primeiro tipo da taxonomia, ou seja, "Relações Pessoais Informais", que o indivíduo que realiza as trocas de informações com a organização seja especificado, demonstrando que pode ser um pesquisador já titulado ou também alunos em fase de titulação em qualquer nível, ou ainda detalhando que esse mediador possa ser das duas formas. $\mathrm{O}$ fato de incluir o aluno nesse contexto torna latente que ele realiza essa conexão entre as IES e as organizações durante a execução de suas pesquisas de campo, pois, principalmente na área de Administração, necessita-se da prática cotidiana das organizações para aplicar ou até mesmo testar a teoria, e que essa pode abrir caminhos para aplicação da inovação como estratégia e para a sustentabilidade organizacional. Sustentabilidade esta não se restringe ao resultado monetário, mas também à prestação de serviços com excelência aos cidadãos e à sociedade como um todo.

A partir disso, percebe-se que as adequações na taxonomia, além de torná-la de fácil compreensão, permitirão a sua ampliação e abrirão espaço para que se aplique além dos limites das organizações de mercado, atingindo as públicas e, por que não, as associativas. Além do mais, possibilitará o reconhecimento de que os alunos, tais como os pesquisadores titulados, também realizam pesquisa e que isso pode levar à inovação.

A partir dessas considerações, observa-se que a taxonomia da relação universidade-empresa de Bonaccorsi e Piccaluga (1994) se comporta de maneira diferenciada quando se consideram organizações que não são empresas, pois, por mais que modelos provenientes de organizações de mercado sejam replicados em alguns casos às organizações públicas e associativas, o sucesso pode ser questionável, devido aos focos diferentes que possuem.

Entretanto, tal como qualquer pesquisa, esta também encontrou algumas limitações, que dificultaram o seu desenvolvimento, tais como: a falta de padronização dos nomes dos programas, comparando aqueles divulgados pela CAPES e os presentes nos sites das IES; e a dificuldade de conseguir as respostas aos questionários, verificando que ainda há a 
resistência, mesmo que o público seja composto por pesquisadores também. Além dessas limitações de pesquisa, houve, também, o fato de que, até onde foi possível pesquisar, tanto na literatura nacional como internacional, não há estudos similares que mencionem a aplicação da taxonomia de Bonaccorsi e Piccaluga (1994) às organizações não mercado, sendo necessária a busca de outras teorias, tal como a de inovação social, para embasar as investigações e análises. Em relação ao comparativo com outros modelos e classificações existentes na literatura, percebeu-se que esse é considerado mais comum entre os grupos de pesquisa, limitando-se por isso em sua análise, já que é amplamente difundido e aplicado.

Logo, foi possível compreender, durante o desenvolvimento do presente estudo, que as correntes funcionalistas e do management ainda prevalecem nos estudos dentro do campo da Administração. Isso faz com que as análises, modelos, métodos e taxonomias possuam como embasamento empírico organizações de mercado que visam resultados monetários, desconsiderando aquelas que não possuem esse propósito, mas que são responsáveis pela manutenção da estrutura da sociedade como um todo, ou seja, aquelas caracterizadas, durante esse estudo, como não mercado, abrangendo as públicas e as associativas. No entanto, a aplicação de modelos elaborados a partir da realidade de organizações de mercado diretamente às organizações públicas ou associativas é de certo modo condenada, já que são contextos totalmente diferentes, como já mencionados.

Portanto, nota-se uma significativa contribuição para o desenvolvimento do conhecimento e ruptura com as perspectivas restritivas ainda imersas no campo da Administração, não com a finalidade de imprimir um caráter generalista à pesquisa, mas para permitir o nascimento de outras questões ainda não respondidas. Além da identificação de limites e possibilidades, bem como o ensaio de possíveis contribuições, levantaram-se questões que podem ser consideradas em proposições de futuros estudos, principal mecanismo para continuar a discussão acerca da taxonomia aqui estudada, uma vez que essa é amplamente adotada por pesquisadores brasileiros. Por isso pergunta-se: como se configuram as relações entre as IES e organizações associativas? Quais as perspectivas das organizações não mercado, bem como de seus dirigentes, perante a interação com a IES por meio dos alunos e também de outros pesquisadores? Qual a perspectiva dos alunos de outros programas de pósgraduação não só stricto sensu, mas 
também lato sensu e em nível de graduação dentro da área de Administração sobre a relação universidade-empresa? E, nas demais áreas do conhecimento, como isso é visto?

Pesquisas que ajudem a avançar no sentido de refletir sobre a questão norteadora da presente pesquisa e sobre as demais que surgiram ao longo dela, tais como essas acima citadas, tendem a contribuir com a construção do campo teórico que sustenta a análise do processo inovativo enquanto estratégia de melhoria contínua e sustentabilidade organizacional.

\section{REFERÊNCIAS}

BARRACHINI, Sabrina Addison. A Inovação presente na Administração Pública Brasileira. RAE: Revista de Administração de Empresas, São Paulo, v. 42, n. 2, p. 104-109, abr.-jun. 2002.

BASTIANI, Scheine Neis Alves da Cruz de. A inovação como estratégia em organizações públicas: limites e possibilidades em relação ao uso da taxonomia de Bonaccorsi e Piccaluga (1994). 2014. 103 f. Dissertação (Mestrado em Administração) - Curso de Mestrado em Administração. UNISUL, Universidade do Sul de Santa Catarina, Florianópolis, 2014.

BIGNETTI, Luiz Paulo. O processo de inovação em empresas intensivas em conhecimento. RAC: Revista de Administração Contemporânea, Curitiba, v. 6, n. 3, p. 33-53, set.-dez. 2002.

BISPO, Marcelo de Souza; GODOY, Arilda Schmidt. A Etnometodologia enquanto Caminho Teórico-metodológico para investigação da Aprendizagem nas Organizações. RAC: Revista de Administração Contemporânea, Rio de Janeiro, v. 16, n. 5, p. 684-704, set.-out. 2012.

\section{BLANCK, Mery; JANISSEK-MUNIZ,} Raquel. Inteligência estratégica antecipativa coletiva e crowdfunding: aplicação do método L.E.SCAnning em empresa social de esconomia peer-to-peer (P2P). R.Adm., São Paulo, v. 49, n. 1, p. 188-204, jan.-fev.-mar. 2014.

BLOCH, Carter. Measuring public innovation in the nordic countries: Copenhagen manual. [s. 1.]: Nordic Innovation, 2010.

BONACCORSI, Andrea; PICCALUGA, Andrea. A theoretical framework for the evaluation of university-industry relationships. R\&D Management, Oxford, v. 24, n. 3, p. 229-247, 1994.

BRANDÃO, Soraya Monteiro; BRUNOFARIA, Maria de Fátima. Inovação no setor público: análise da produção científica em periódicos nacionais e internacionais da área de administração. Rev. Adm. Pública, Rio de Janeiro, v. 47, n. 1, p. 227-248, jan.-fev. 2013.

COOPER, Donald R.; SCHINDLER, Pamela S. Métodos de Pesquisa em Administração. 7. ed. Porto Alegre: Bookman, 2003.

\section{CRESWELL, John W. Projeto de} pesquisa: Métodos qualitativo, quantitativo e misto. 2.ed. Porto Alegre: Artmed, 2007.

DAGNINO, Renato. A relação universidade-empresa no Brasil e o "Argumento da Hélice Tripla". Revista Brasileira de Inovação, São Paulo, v.2, n. 2, p. 267-307, jul.-dez. 2003. 
DESIDERIO, Paulo Henrique Martins; ZILBER, Moisés Ari. Barreiras no processo de transferência tecnológica entre agências de inovação e empresas: observações em instituições públicas e privadas. In: Simpósio de Administração da produção, Logística e Operações Internacionais, 27, 2014, São Paulo. Anais eletrônicos... São Paulo, 2014.

DIAS, Taisa. Governança Pública: uma concepção teórico-analítica aplicada no governo do Estado de Santa Catarina a partir da implantação das Secretarias de Desenvolvimento Regional. 2012. 353 f. Tese (Doutorado em Administração) Curso de Doutorado em Administração. UFSC, Universidade Federal de Santa Catarina, Florianópolis, 2012.

DIAS, Taisa; CARIO, Silvio Antonio Ferraz. A Relação entre Estado e Sociedade no Século 21: a perspectiva paraeconômica como estratégia neodesenvolvimentista. Desenvolvimento em Questão, Ijuí, RS, v. 12, n. 27, p. 370403, jul.-set. 2014.

ETZKOWITZ, Henry. Innovation in innovation: the triple helix of universityIndustry- government relations. Social Science Information, [s. 1.], v. 42, n. 3, p. 293-337, set. 2003.

The triple helix of universityindustry-government implications for policy and evaluation. Working paper, Institutet för studier av utbildning och forskning, Stockholm, nov. 2002.

ETZKOWITZ; KLOFSTEN, Magnus. The innovating region: toward a theory of knowledge-base regional development.

R\&D Management, Oxford, v. 35, n. 3, p. 243-255, jun. 2005.

FIEDLER, Ligia. Gestão de ideias para inovação. RAC: Revista de Administração Contemporânea, Curitiba, v. 15, n. 1, p. 173-175, jan.-fev.,
2011.

FRANÇA-FILHO, Genauto Carvalho de. Para um olhar epistemológico da administração: problematizando o seu objeto. In: SANTOS, Reginaldo. S. (org). A administração pública como campo do conhecimento. São Paulo: Mandacaru, 2004.

FREITAS, Rony Klay Viana de; DACORSO, Antonio Luiz Rocha. Inovação aberta na gestão pública: análise do plano de ação brasileiro para a Opern Government Partnership. Rev. Adm.

Pública, Rio de Janeiro, v. 48, n. 4, p. 869888, jul.-ago. 2014.

GONÇALO, Cláudio Reis; ZANLUCHI, João. Relacionamento entre empresa e universidade: uma análise das características de cooperação em um setor intensivo em conhecimento. Revista de Administração e Contabilidade da Unisinos, São Leopoldo, RS, v. 8, n. 3, p. 261-272. jul.-set. 2011.

JACOBI, Pedro; PINHO, José Antonio. Inovação no campo da gestão pública local: novos desafios, novos patamares. Rio de Janeiro: Editora FGV, 2006.

KLERING, Luis Roque; ANDRADE, Jackeline Amantino de. Inovação na gestão pública: compreensão do conceito a partir da teoria e da prática. In: JACOBI, Pedro; PINHO, José Antonio. Inovação no campo da gestão pública local: novos desafios, novos patamares. Rio de Janeiro: Editora FGV, 2006.

LEYDESDORFF, Loet; ETZKOWITZ, Henry. The Transformation Of Universityindustry-government relations. Electronic Journal of Sociology, United States, v. 5, n. 4, 2001.

LIMA, Dagomar Henriques; VARGAS, Eduardo Raupp de. Estudos internacionais 
sobre inovação no setor público: como a teoria da inovação em serviços pode contribuir?. RAP, Rio de Janeiro, v. 46, n. 2, mar.-abr. 2012.

MEC, Ministério da Educação. Qual é a diferença entre faculdades, centros universitários e universidades?

Disponível em:

$<$ http://portal.mec.gov.br/index.php? option $=$ com_content $\&$ view $=$ article $\&$ id $=11$ $6 \&$ Itemid=86> . Acesso em: 28 out. 2014.

MORGAN, Gareth. Paradigmas, metáforas e resolução de quebra-cabeças na teoria das organizações. RAE: Revista de Administração de Empresas, São Paulo, v. 45, n. 1, p. 58-71, jan.-mar. 2005.

MORIN, Edgar. O problema epistemológico da complexidade. Lisboa: Europa-América, 1996.

MOTA, Teresa Lenice Nogueira da Gama. Interação universidade-empresa na sociedade do conhecimento: reflexões e realidade. Revista Ciência da

Informação, Brasília, v. 28, n. 1, p. 79-86, 1999.

MRE, Ministério das Relações Exteriores.

Denominações das Instituições de Ensino Superior (IES). Disponível em: $<$ http://www.dce.mre.gov.br/nomenclatura _cursos.html>. Acesso em: 28 out. 2014.

NELSON, Richard R. As fontes do crescimento econômico. São Paulo: Unicamp, 2006.

Capitalism as an engine of progress. Research Policy, v. 19, n. 3, p. 193-214, jun. 1990.

NELSON, Richard R; ROSENBERG, Nathan. Technical innovation and national systems. In: NELSON, Richard R.

National innovation systems: a comparative analysis. New York: Oxford University, 1993.
NUNES, Marcelo Saraceni. Inovação Estratégica nas Instituições de Ensino Superior no Brasil. 2009. 116 f. Tese (Mestrado em Gestão de Empresas) Curso de Mestrado em Gestão de Empresas. ISCTE, Instituto Superior de Ciências do Trabalho e da Empresa, Lisboa, 2009.

PHILLS JR, James A.; DEIGLMEIER, Kriss; MILLER, Dale T. Rediscovering Social Innovation. Stanford Social Innovation review, 2008.

PLONSKI, Guilherme Ary. A inovação e as Demandas Sociais. In: MARCOVITCH, Jacques (Org.). Crescimento econômico e distribuição de renda: prioridades para ação. São Paulo: SENAC São Paulo, 2007.

PUFFAL, Daniel Pedro. Os determinantes da interação universidade-empresa e o desenvolvimento tecnológico das empresas. 2011. $172 \mathrm{f}$. Tese (Doutorado em Administração) - Curso de Doutorado em Administração. UNISINOS, Universidade do Vale dos Sinos, São Leopoldo, RS, 2011.

RICHARDSON, Roberto Jarry. Pesquisa social: métodos e técnicas. 3.ed. São Paulo: Atlas, 2008.

ROSENBERG, Nathan. Por dentro da caixa preta: tecnologia e economia. Campinas-SP: Editora Unicamp, 2006.

SCHWELLA, Erwin. Inovação no governo e no setor público: desafios e implicações para a liderança. Revista do Serviço Público, Brasília, v. 56, n. 3, p. 259-276, jul.-set. 2005.

SEGATTO-MENDES, Andréa Paula; SBRAGIA, Roberto. O processo de cooperação universidade-empresa em universidades brasileiras. Revista de Administração, São Paulo, v. 37, n. 4, 
p.58-71, out.-dez. 2002.

SUZIGAN, Wilson; ALBUQUERQUE, Educardo da Motta e; CARIO, Silvio Antonio Ferraz. Em busca da inovação: interação universidade-empresa no Brasil. Belo Horizonte: Autêntica, 2011.

TRIVIÑOS, Augusto N. Introdução à pesquisa em ciências sociais: a pesquisa qualitativa em educação. São Paulo: Atlas, 2011.

VARGAS, Eduardo R. Disseminação de iniciativas inovadoras premiadas no Concurso Inovação na Gestão Pública Federal (1996-2006). Cadernos Enap, Brasília, n. 34, p. 58-115, 2010.

VIEIRA, Marcelo Milano Falcão; ZOUAIN, Deborah Moraes. Pesquisa qualitativa em administração. 2. ed. Rio de janeiro: Editora FGV, 2006. 